\title{
The role of civil society organisations (CSOs) in healthcare delivery system: A case study of child immunisation in Kabarole district, Uganda
}

\author{
Clovice Kankya ${ }^{1,2^{\star}}$, Annah Akandinda ${ }^{2}$, Charles B. Rwabukwali ${ }^{2}$ \\ ${ }^{1}$ Department of Biosecurity, Ecosystems and Veterinary Public Health, College of Veterinary Medicine, Animal Resources and Bio- \\ security (COVAB), Makerere University, Kampala, Uganda; ${ }^{*}$ Corresponding Author: clokankya@yahoo.com \\ ${ }^{2}$ Department of Sociology and Anthropology, College of Humanities and Social Sciences (CHUSS), Makerere University, Kampala, \\ Uganda; akandinda@gmail.com, crwabukwali@ss.mak.ac.ug
}

Received 22 May 2013; revised 30 June 2013; accepted 20 July 2013

Copyright (c) 2013 Clovice Kankya et al. This is an open access article distributed under the Creative Commons Attribution License, which permits unrestricted use, distribution, and reproduction in any medium, provided the original work is properly cited.

\section{ABSTRACT}

Background: The importance of civil society organisations in health care delivery systems cannot be under-rated in sub-Saharan Africa and other developing nations worldwide. Civil society organisations play a central role in service delivery and development of democracy. However, little is known about the roles and achievements of Civil Society Organisations (CSOs) in healthcare. The study aimed at exploring the role of civil society organisations in health care delivery system particularly in children immunization. Methods: A questionnaire survey involving 282 households was conducted. Data were analysed using descriptive statistics followed by multivariable logistic regression. Results: Ninety seven percent $(97 \%)$ confirmed that CSOs/NGOs healthcare facilities played a major role in healthcare service delivery. $84 \%$ travelled long distances to access the healthcare services including child immunisation services. Travelling long distances $(>2 \mathrm{~km})$ to access for health care services including immunization compared to short distance $(<1 \mathrm{~km})(O R=0.4, P=0.0001)$, possessing a food stores (enguli) compared to not having a food store (enguli) $(O R=2.3, P=0.002)$, having separate animal houses compared to not having livestock houses $(O R=0.09, P=0.0001)$, and owning a bicycle compared to not having a bicycle (OR $=2.2, \mathrm{P}=0.005)$ are important determinants for the number of clients at CSO health centers. Further, possessing and using a cellphone compared to no cellphone $(\mathrm{OR}=3.7, \mathrm{P}$ $=0.001)$, Possessing and watching a television compared to not having a television $(O R=2.4, P$ $=0.002$ ), educated compared to not acquiring any formal education $(O R=0.084, P=0.0001)$, and female compared to male respondent $(O R=$ $0.49, P=0.0045$ ) are other most important factors likely to determine the numbers of clients at the CSO healthcare. Conclusion: Geographies of CSO and community socioeconomics strongly determine the operations and the roles played by the CSO healthcare services in Uganda. Further studies to assess the role of CSO health service providers in other healthcare services need to be done.

Keywords: Civil Society Organization (CSO); Healthcare; Kabarole district; Uganda

\section{INTRODUCTION}

Civil Society Organisations (CSOs) are defined as non-state, not-for-profit, voluntary organisations formed by people within the social sphere of civil society [1]. Therefore, the term CSO is also used interchangeably with non-governmental organisations (NGOs). While the term CSOs cover a variety of organisational interests and forms, which can include also informal social movements coming together around a common cause, the NGOs usually have a formal structure and in most cases, they are registered with national authorities [2].

On the other hand, Health system consists of all organizations, people and actions whose primary intent is to promote, restore or maintain health. This includes efforts to influence determinants of health as well as more direct health-improving activities. Health care providers are institutions or individuals providing health care services. 
Individuals include health professionals and allied health professions (self-employed or working as an employee) in a hospital, clinic, or other health care institution, whether government operated, private for-profit, or private notfor-profit (e.g. non-governmental organization). Therefore, healthcare is considered adequate, if there is an emphasis on illness prevention and health promotion as well in addition to treatment [3]. Hospitals are very important elements of health care system and dominate the rest of the healthcare [4].

Globally over the last decades, the role of CSOs in service delivery and those particularly involved in health service delivery in particular has undergone dramatic change in both developing and industrialized countries [5]. It is impossible to define the role of CSO in health sector without first considering the role of government and the strengths and weakness in the current health care delivery systems. CSOs in the recent years have become more prominent, visible and diverse [2,6]. Historically, civil society organisations have been associated with the rise of democracy in both Europe and North America. CSO is a product of a specific historical evolution associated with the enlightenment and subsequent elements of modernization notably urbanization, industrialization, and the rise of modern capitalism [7-9]. As a result, CSO networks have been formed within and across countries to promote a wider and more transnational support of public interests on global policy issues such as human rights, environment, democracy, development and health $[6,10]$. All these are aimed at fostering improved service delivery, democracy, social and economic development.

In Asia and Latin America, CSOs have been involved in mobilizing effective demand for services, building awareness of community needs and experimenting in innovative approaches to service delivery that are later replicated by the government sector [11].

In Africa, African states had failed to foster sustainable development hence causing the re-emergence of the idea of CSOs. CSO represents a sustained political reform, legitimate states and governments, improved governance and service delivery systems. Civil society is observed as a priority for any form of sustainable change. It is argued that in governments where decentralization is practiced [12]. CSO engagement has led to a more responsive, accountable and transparency system responsible for sustainable development.

Among other tasks, CSOs have assisted in working with the government to integrate evidence-led health planning and community preferences. Therefore, general reports indicate that CSOs play a major role in the delivery of health services.

In Uganda, there has been a tremendous growth in nongovernmental organizations and with the many reforms presently taking place. Uganda's poverty and underde- velopment is manifested in poor health indicators and civil society organizations play a central role in both service delivery and the development of democracy [13]. The complexity and the dynamics of civic sector in Uganda are diverse [14].

Therefore, what remains unanswered is the role of Civil Society Organisations (CSOs) in health care delivery systems? Consequently, this calls for highlighting work that has been done by civil society organisations (CSOs), analyzing areas for improvement in various aspects of CSO in health care and health delivery systems as well as explore ways in which CSOs can strengthen their existing work to bolster health care systems.

Of late, emerging concern about CSOs highly donordependent and outcry in the public arena is that some CSOs have a narrow membership base and weak links to the constituencies they are meant to serve. These are commonly referred to as "Briefcase CSO or NGOs". Besides these community concerns, many CSOs and their networks have fragile institutional foundations in areas such as governance, strategic planning, human resource management and financial management [13]. In addition, CSOs capacity for effective advocacy is also limited. This case scenario therefore, presents a challenge in ascertaining CSOs and their roles in health care delivery systems especially in the developing countries such as Uganda [15].

In industrialized and developing countries, provision of social services such as health care and health service delivery has been a fulcrum role that CSOs have customarily played. While CSOs provide many forms of support to communities including health, religious, educational, literary, agricultural and social development, CSOs still have faced major challenges that accrue from providing services to people that governments has failed to reach out to.

In Uganda, during the period of relative peace ranging from 1986 to date, there has been a rapid proliferation of both indigenous and international CSOs as well as a shift in focus of the CSOs activity from relief, through service provision to other national developmental activities [16]. While the healthcare system is dominated by public facilities, the actual healthcare usage and access present a different picture. In the Ugandan context, faith-based or religious non-governmental organizations (NGOs) have had a long history of health service provision while other organizations have become more involved in recent years. Despite all these contributions, there are no studies showing the operations and the roles of CSOs in health care delivery systems and their impacts despite the long existence of CSOs. There is need to provide an understanding whether CSOs are problem or provide solution in health care delivery system in Kabarole district, Uganda. How- 
ever, we notice that neither much documentation nor much critique has been done so far to assess whether CSOs is a blessing or curse to Uganda with regard to health care delivery system. Therefore, it is against this background that the study is designed to assess the roles of CSOs in health care delivery systems, particularly in immunisation of children in Kabarole district, Uganda.

\section{MATERIALS AND METHODS}

\subsection{Study Areas and Selection}

The study was carried out in Kabarole district, Uganda between the months of January to March 2013. Kabarole District is a first-order administrative division (class A Administrative Region. It is located at an elevation of 1470 meters above sea level. Its coordinates are $0^{\circ} 34^{\prime} 60^{\prime \prime} \mathrm{N}$ and $30^{\circ} 15^{\prime} 0^{\prime \prime} \mathrm{E}$ in Degrees Minutes Seconds (DMS). Kabarole district was chosen basing on the population density and the number of children in the district [17]. Secondly, Kabarole district has a wide range of NGOs and CBOs registered under the umbrella Kabarole NGOs and CBOs Association (KANCA) especially those dealing in healthcare service provision.

This study employed a cross-sectional survey design that collected data using quantitative and qualitative approaches. This study design involved collecting data at that defined time where the researcher recorded the information present at the CSOs involved in health care delivery in relation to children immunisation in Kabarole district population. The primary study unit was the household represented by an individual from each. The selection of study household was done from a list of households served by the two selected CSOs.

A total of 282 individuals (each a proxy for a household) were interviewed using standardised questionnaires. Of the 323 respondents designed and planned to be involved in the cross-sectional study, 41 (12.7\%) were not accessible for interviews and thus no data was gathered from them. Therefore, the total study population comprised of 282 respondents. The study population included household/individuals (Bunyangabu and Burahya counties and Fortportal municipality) who accessed or access the services from the two purposively selected CSOs. Data was collected and documented using the household survey questionnaire.

The questionnaire included the following aspects; general background information, household access to social services including health care services, household occupancy, occupation, items owned and income sources, distances travelled to access the social services, rating of the CSOs involved in healthcare service delivery.

The questionnaire was set up in English, translated to local language (Rutooro) before use and retranslated to
English. This process allowed standardisation of responses. In order to ensure correct filling of the questionnaire forms and appropriate data compilation and entry, trained interviewers administered the questionnaire in the local language to each participant. Administration of the questionnaires was done with the assistance from the two research assistants. The research assistants were trained, guided and supervised on the procedures of using the designed study instruments.

\subsection{CSOs Selection Criteria}

The researcher during the reconnaissance survey purposively selected two different types of CSOs in the study area. One locally- funded CSO and one internationally funded based in Kabarole district. Kitojo Integrated Development association (KIDA) (local-small sized, rural based and international-funded,) hospital and Hoy Family Virika (Medium to Large sized, urban-based and locally- funded) hospital, in Kabarole district were purposely selected. Furthermore, the two case CSOs vary in geographical locations of the rural-based setting versus urban-based setting. This provided a comparative basis while analyzing the operations of the CSO in delivering children immunisation health care services. The selected CSOs/NGOs were based in Kabarole district and dealing in health care delivery services especially children immunization health care services. Of these two purposively selected CSOs, the physical and organization structures were studied and results obtained will be presented in the subsequent paper.

\subsection{Sampling Strategy}

The primary study unit was the household represented by an individual from each. The selection of study household was purposively selected based on the list of households served by the selected CSOs from the records of the CSOs.

Using a sample size formula by Kish Leslie for crosssectional studies [18].

$$
\mathrm{n}=\frac{\mathrm{Z}^{2} \mathrm{pq}}{\mathrm{e}^{2}}
$$

where $\mathrm{n}=$ required sample size;

$\mathrm{Z}=$ the normal curve constant that represents the level of confidence (1.96);

$\mathrm{E}=$ the desired level of precision estimated at 95\%;

$\mathrm{p}=$ the estimated proportion of attribute that is present in a population (70\%) and $\mathrm{q}$ is the $1-\mathrm{p}$.

In this study, we estimated the allowable error margin at $5 \%(0.05)$. This therefore results into the confidence interval at $95 \%$. It is also estimated that $70 \%$ of the population accesses the healthcare services from the CSOs in Kabarole district. 


$$
\mathrm{n}=\frac{1.96^{2}}{0.05^{2}} \times 0.7 \times 0.3
$$

By substituting for $n=323$ individuals/households.

Therefore a total of 323 individuals (each a proxy for a household) were interviewed using standardised questionnaires in the quantitative approach.

\subsection{Pre-Testing Process}

Prior to data collection, well designed research tools were tried out by pre-testing on individuals experiencing similar environments as the study population. For this study, pre-testing was done in Kyenjonjo district, Butiti Sub County, Mbale parish, Mugoma village. The pre-test sample was however not used for final sampling of the study. The pre-testing process provided the researcher an opportunity to assess the error that would have been made during the construction of research tools such as inaccurate wording, coding, interviewers' bias, trimming of the relatively lengthy questionnaires, all these anomalies were corrected, deleted and omitted.

\subsection{Data analysis and Management}

A database consisting of questionnaire data was established in Microsoft Excel ${ }^{\circledR}$.The physical and organisational structures of the two selected CSOs in Kabarole district were documented. Further statistical analysis was carried out using Stata version 11/SE for Windows (Stata Corp, College Station, TX). Descriptive statistics were computed and presented. The outcome of interest was further statistically analysed using regressions to assess the roles of the CSOs in healthcare delivery among the community of Kabarole district.

Ethical considerations were given top priority, a clearance letter for conducting the study was obtained before commencement of the study from the school of Sociology and Anthropology, committee at Makerere University. Furthermore, a letter authorising data collection process to be carried out in the study district was also obtained from the office of the chief Administrative Officer (CAO), Kabarole district with the Quote Ref. No. CR/D/11015. This letter was further endorsed by the Head of health care delivery services in Kabarole district; The District Health Officer (DHO). In addition, when administering questionnaires to the study respondents, issues of informed consent was first sought. It was also made clear that issues of confidentiality were adhered to when conducting this study and the purpose for which the study was carried out, was communicated to the respondents.

\section{RESULTS}

A number of socio-demographic characteristics and their levels of analysis were recorded. These included gender, ages of the respondents, education levels, and marital status of the respondents, household composition, livelihood and income sources and household asset-bases of the survey respondents (Table 1). Results from descriptive statistics (Table 2) revealed that the respondents were mainly females consisting of $78 \%$ respondents (220/ 282 ) while only $22 \%$ (66/282) were males. Ages of the respondents: The majority of the respondents who participated in this survey fell between 21 - 40 years of age and constituted of $66 \%$ of the total respondents interviewed. The results further indicated that below 20 years were constituted only 22\% while between 41 - 60 years old as well as over 60years of age comprised of only $6 \%$.

Marital status: The majority of the respondents were married and living with their spouses (76\%). While, 15\% of the respondents were married but their spouses do not live there at the time of interviews, $3 \%$ were either widowed or widower and 6\% were not married at all.

Education level: The respondents education levels varied from primary school education- $19 \%$ below primary four, $31 \%$ primary seven level ) to ordinary level (90/282 i.e. $32 \%$ of the respondents) of type of formal education. In addition, this study registered respondents with advanced level 25/282, i.e. (9\%) and with 9 out of the 282 of the respondents, i.e. $3 \%$ had acquired up to tertiary level of education.

Table 1. Levels of the socio-demographic characteristics of the respondents.

\begin{tabular}{ll}
\hline Sociodemographic variable & Levels \\
\hline County & Bunyangabu, Burahya and Fortportal municipality \\
Sex/gender & Male, female \\
Marial status & $\begin{array}{l}\text { Married living with the spouse, married but the spouse away, Divorced, } \\
\text { widow/widower, Not married } \\
\text { No formal education, <P4, P5 - P7, Ordinary level, Advanced level, }\end{array}$ \\
Education category & $\begin{array}{l}\text { Tertiary level and above } \\
\text { Ages of the respondents }\end{array}$ \\
Occupation, household livelihood and income sources & $\begin{array}{l}\text { Government sector, NGO sector, Private sector ( business and merchandise), } \\
\text { Crop and livestock-based Small to medium enterprises(SMEs) } \\
\text { Household composition }\end{array}$ \\
\hline
\end{tabular}


Table 2. Socio-demographic characteristics of the respondents $(\mathrm{N}=282)$.

\begin{tabular}{|c|c|c|c|}
\hline Variables & Levels & Frequency & $\%$ \\
\hline \multirow{3}{*}{ County } & Bunyangabu & 96 & (34) \\
\hline & Burahya & 87 & (31) \\
\hline & Fortportal Municipality & 99 & (35) \\
\hline \multirow{2}{*}{ Gender } & Male & 66 & $(22)$ \\
\hline & Female & 220 & (78) \\
\hline \multirow{5}{*}{ Marital status } & Married living with the spouse & 214 & (76) \\
\hline & Married but the spouse away & 41 & (15) \\
\hline & Divorced & 0 & (0) \\
\hline & widow/widower & 9 & (3) \\
\hline & Not married & 18 & (6) \\
\hline \multirow{6}{*}{ Education category } & None & 18 & (6) \\
\hline & $<\mathrm{P} 4$ & 53 & (19) \\
\hline & P5 - P7 & 87 & (31) \\
\hline & Ordinary level & 90 & (32) \\
\hline & Advanced level & 25 & (9) \\
\hline & Tertiary level & 9 & (3) \\
\hline \multirow{4}{*}{ Ages of respondents } & $<20$ & 62 & (22) \\
\hline & $21-40$ & 186 & (66) \\
\hline & $41-60$ & 17 & (6) \\
\hline & $>60$ years & 17 & (6) \\
\hline \multirow{4}{*}{$\begin{array}{l}\text { Occupation, household livelihood } \\
\text { and income sources }\end{array}$} & Government sector & 8 & (3) \\
\hline & NGO sector & 9 & (3) \\
\hline & Private sector involving business and merchandise & 75 & (27) \\
\hline & Crop and livestock-based Small to medium enterprises(SMEs) & 190 & (67) \\
\hline \multirow{6}{*}{ Household composition } & $<4$ persons & 43 & (15) \\
\hline & 5 persons & 43 & (15) \\
\hline & 6persons & 76 & (27) \\
\hline & 7persons & 68 & (24) \\
\hline & 8 persons, & 18 & (6) \\
\hline & Nine persons \&above & 34 & $(12)$ \\
\hline
\end{tabular}

Household livelihood: Of the 282 respondents, 190 respondents (67\%) derive their livelihood from agriculture and livestock related small scale to medium enterprises (SMEs). This is through selling the produce from these two enterprises. However, there are 75 out of 282 respondents who are involved in business and other merchandise ventures in order to raise household incomes.
Household composition: On average, respondents household are composed of 6 - 7 persons. Seventy six respondents out of the total study population (76/282) i.e. $27 \%$ had occupancy of household numbers lying at 6 persons including children while $68 / 282$ i.e. $24 \%$ of the respondents had the number of people in a household at 7 persons. In this survey, respondents who had household population below four and or five (5) persons represented 
43 out of 282, i.e. $15 \%$ of the respondents in both cases.

Results obtained from the household asset base of the respondents. A wide range of items in various categories were owned by surveyed households and these items facilitated or impeded easy access to healthcare services (Table 3).

Communication: These include communication related items: Radio, All the respondents 282(100) confirmed that everyone owned a radio as a means of communication. Television: Functional television (TV) was present in only 75 households (27\%), the rest of the respondents (207) i.e. 73\% households did not own a television (TV). Cell phones: (landlinesor cellphones): At the time of interview, seventy five percent of the respondents (212/282) owned cellphones. Twenty five (25\%) percent not own any cellphones. No land line phone was evidenced at household level during the study.

Transport: Vehicle: Functional vehicle was present in only 18 households of the 282 households interviewed, i.e. (6\%) of the respondents, while the rest of the respondents (264/282) i.e. 94\% households did not own a vehicle at the time of interview. Motorcycle: Motorcycles were owned in only 92 households of the 282 households interviewed i.e. (33\%) of the respondents, while the majority (190/282) i.e. $67 \%$ of the respondents' households did not own a motorcycle at the time of interview. Bicycle: More than half of the respondents owned bicycles, i.e. 158 of the 282 households interviewed, i.e. (56\%) of the respondents, while the rest of the respondents (124/282), i.e. $44 \%$ of the respondents' households did not own a bicycle at the time of interview.

Shelter: Main house and Kitchen: All the respondents 282(100) confirmed that everyone had shelter in form of the main house and the kitchen a means of shelter and food preparation site for the family. The main roofing materials varied from grass to iron sheets. The number of respondents with grass-thatched main houses were 27/282 fetching $10 \%$ of the respondents whereas 255 out of the 282 respondents, i.e. 90\% possessed iron sheet roofed main houses. The walls and floor of the main house of the respondents were as follows: 143 out of 282 respondents (51\%) with mud walled with cow dung smeared floors and 139 out of 282 respondents (49\%) had brick-walled and cemented main houses.

Water and sanitation facility-Possession of a toilet: All the respondents 282 (i.e. 100\%) confirmed that everyone had a toilet as a means of sanitation and hygiene maintenance measure at household level. From observations, the structures of toilets and the main houses varied according to the potential and the economics of the households.

Water tank: Only thirty five percent of the respondents owned, i.e. 98 out of the 282 respondent households owned the water tanks (plastic and metallic types), the rest of the respondents $184 / 282$ i.e. (65\%) of the respondents

Table 3. Household capabilities (asset-base) related to access general health care services including access to immunisation centres $(\mathrm{N}=282)$.

\begin{tabular}{|c|c|c|c|}
\hline Variable category & Item & Present Frequency (\%) & Absent Frequency (\%) \\
\hline \multirow{3}{*}{ Communication } & Radio & $282(100)$ & - \\
\hline & Television & $75(27)$ & 207(73) \\
\hline & Cellphone & $212(75)$ & $70(25)$ \\
\hline \multirow{3}{*}{ Transport } & Bicycle & $158(56)$ & $124(44)$ \\
\hline & Motorcycle & $92(33)$ & 190(67) \\
\hline & Vehicle & $18(6)$ & 264(94) \\
\hline \multirow{5}{*}{ Shelter } & Main house & $282(100)$ & - \\
\hline & Kitchen & $282(100)$ & - \\
\hline & Toilet & $282(100)$ & - \\
\hline & Water tank & $98(35)$ & $184(65)$ \\
\hline & Food store (enguli) & $127(45)$ & $155(55)$ \\
\hline \multirow{5}{*}{ Utilities and social services } & Electricity & $157(56)$ & $125(44)$ \\
\hline & Piped water & 107(38) & 175(62) \\
\hline & Agric/crop extension services & 202(72) & $80(28)$ \\
\hline & Livestock extension services & $210(74)$ & $72(26)$ \\
\hline & Microfinance services & $210(74)$ & $72(26)$ \\
\hline
\end{tabular}


household did not have a water tank. Water tanks were used to collect or harvest water from to roof tops whenever it rains.

Food stores: Presence of food stores commonly and locally called enguli. Only 127/282 i.e. 45\% confirmed having functioning food stores (enguli) in place. Household in possession of functioning food store (Enguli) have food security measures and are assured of improved nutrition and health, especially in event of scarcity of food. In this regard, it was unfortunate that one hundred fiftyfive (155/282) households i.e. 55\% which is more than half of the respondents did not have food stores (enguli) at the time of interview (Table 3).

As far as utilities and social services are concerned, table 3 further presents the results as follows: Electricity: More than half of the respondents who participated in this survey had access to electricity, 157 out of 282 (56\%) and the rest $34 \%$ did not have access to the electricity/power services. Piped water: Only 107/282 of the respondents (38\%) had access to piped water, while 175/282 of the respondents (62\%) did not have any access to piped water. This proportion depended on other water sources for drinking and domestic use e.g. rivers, springs and community wells. Agricultural-crop extension services: A total of 202 out of the 282 respondents i.e. $72 \%$ had access to agricultural extension services through the National Agricultural Advisory services (NAADS) program. Livestock and microfinance services: Respondents had access to livestock extension services through local government vet services as echoed by 210 respondents out of the 282 respondents i.e. $74 \%$ and a similar percentage of $74 \%$ respondents had access to microfinance services and social groups for savings and credit services.

Furthermore, all the respondents had access to the social services however, the distances travelled by individuals to access the social services varied accordingly and were captured using this survey (Table 4).
Healthcare centers: The distances taken to access the health care facilities (including child immunization centers) ranged as follows: Below or in one kilometers distance has only 44/282 respondents i.e. (16\%) while sixty one (61/282) respondents i.e. (22\%), travelled an average of $2-3 \mathrm{Km}$. The study further revealed that eight five (85/282) respondents, i.e. 30\% travelled a distance of about 4-5 Kilometers in order to access the immunization centers. Ninety two out of the 282 respondents, i.e. 32\% of the respondents travelled relatively long distances of approximately 6 - 10 kilometers in order to access the healthcare services.

Education-Primary education: The distance travelled by the respondents to access primary schools were follows: Below or in one kilometers distance has only 111/ 282 of the respondents i.e. (39\%). Sixty seven while 67 respondents (24\%), travelled an average of 1 - 2 kilometre (Km), Sixty eight (68) respondents i.e. $24 \%$ travelled a distance of about 4 - 5 Kilometers to access the education at primary school level. Only 36 of the respondents i.e. $13 \%$ of the respondents travelled a distance of approximately 6 - 10 kilometers in order to access the education services at primary school level.

Markets: Markets are distant located from most individuals of the community, i.e. 92 out of 282 of respondents moved a distance not less than $2 \mathrm{~km}$. similarly 85 out of 282 respondents walked a distance of about $5 \mathrm{~km}$ in order to access the markets. However, there is a proportion of 61 respondents out of 282, i.e. $22 \%$ of the respondents who travelled a relatively very short a distance, only less than one kilometer in order to access to the market services.

Main roads: The majority of the respondents had access to main roads, i.e. 135 out of 282 respondents to reach the main road were short below or in $1 \mathrm{~km}$ distance. However, about 102 and 36 out of the 282 respondents travelled a distance of 2 - $3 \mathrm{~km}$ and 4 - $5 \mathrm{~km}$ respectively in order to access the main road. The main roads are important in that

Table 4. Distance travelled by the community for access of social services $(\mathrm{N}=282)$.

\begin{tabular}{|c|c|c|c|c|c|}
\hline Distance (Km) & No. Respondents, ( \%) (Below 1Km) & $(2-3 \mathrm{Km})$ & $(4-5 \mathrm{Km})$ & $(6-10 \mathrm{Km})$ & $>10 \mathrm{Km}$ \\
\hline Healthcare services & $44(16)$ & $61(22)$ & $85(30)$ & $92(32)$ & - \\
\hline Primary school & 111(39) & $67(24)$ & $68(24)$ & $36(13)$ & - \\
\hline Market & $61(22)$ & $91(32)$ & $85(30)$ & $36(13)$ & $9(3)$ \\
\hline Main road & 135(48) & 102(36) & $36(13)$ & $9(3)$ & - \\
\hline Electricity & $97(34)$ & 149(53) & $36(13)$ & - & - \\
\hline Agricultural/crop extension services & $52(18)$ & $95(34)$ & $126(45)$ & $9(3)$ & - \\
\hline Livestock services & $61(22)$ & 104(37) & $66(23)$ & $51(18)$ & - \\
\hline Microfinance services & $54(19)$ & 105(37) & $65(23)$ & $58(21)$ & - \\
\hline $\begin{array}{l}\text { Community Water sources } \\
\text { (rivers, springs, and wells) }\end{array}$ & $79(28)$ & 109(39) & $58(21)$ & $36(13)$ & - \\
\hline
\end{tabular}


they are the ones with major public transport means such as buses and taxis which allow people access goods and services including access to healthcare and other services.

Electricity: 149 out of the 282 respondents can access electricity in a distance of about $2-3 \mathrm{~km}$, while only ninety seven out of the 282 have electricity accessed in a distance of less than $1 \mathrm{~km}$. However, approximately 36 out of the 282 had very limited access to electricity as it was located in a 4 - $5 \mathrm{~km}$ distance.

Uniquely, agricultural services were difficult to access by the majority of the respondents as 126 out of the 282 respondents i.e. $45 \%$ of the respondents traveled a distance of about 4 - $5 \mathrm{~km}$. More than 100 out of the 282 respondents would access livestock extension services , Microfinance services and be able access the water sources after travelling a distance of about 2 - $3 \mathrm{Km}$.

Multivariate logistic regression analysis (Table 5) showed that CSO healthcare plays a key role in child immunization and other general health care service delivery system in Kabarole district, Uganda. Results indicated that gender is significantly associated with rating of CSO hospital healthcare services with a p-value of 0.045 . With the odds ratio less than 1 , means that females are 0.49 times less likely to rate the CSO in health care service delivery better compared to their male counterparts (since males are coded 1 and females coded 0 ). As far as education level is concerned, educated community members are 0.72 times less likely to rate the CSO better than those that are not educated. This relation is statistically significant with a p-value of 0.004 and 95\% CI of 0.56 0.89. Further, we observed that there is a significant relationship between distance to health facility and rating of CSO. Individuals who travelled more than one $\mathrm{km}$ (2 above) are 0.41 times less likely to rate the services of CSO as better compared to those individuals who stay less than $1 \mathrm{~km}$ from the CSOs hospitals. This relationship is highly significant with a p-value of 0.001 and $95 \%$ CI of $0.29-0.56$.

As far as the socioeconomic status is concerned, mul- tivariable logistic regression revealed that those households who have televisions and who watch at home are 2.4 times more likely to rate the activities of CSOs healthcare as good. The findings were highly significant with a p-value of 0.002 and 95\% CI of 1.38 - 4.19. Further, respondents who had cellphones are 3.7 times more likely to rate the activities of CSOs as better and have access to the CSO healthcare services compared to those who don't have cellphones. This result showed a high significance with a p-value of 0.001 and 95\% CI of $1.75-7.89$. Households with bicycles as modes of transport to the health center are 2.2 times more likely to rate and value the role of CSOs health care services compared to those who did own a bicycle as means of transport commonly used to access health services. This relation is statistically significant with a p-value of 0.005 and 95\% CI of 1.27 3.75 .

Multivariable logistic regression results indicated that households with food stores (eguli) are 2.3 times likely to rate the CSO health care facilities as better than those who do not have a food stores. This is also highly significant with a p-Value of 0.002 and confidence interval at 95\% CI of 1.37 - 3.89. Having separate animal house (Kraal) for livestock is 0.09 times less likely to rate the CSO healthcare better than those without animal houses (kraals). This relation is statistically significant with a p-value of 0.0001 and $95 \%$ CI of $0.042-1.99$.

CSOs in health care played key role in health care delivery services including child immunisation in Kabarole district. The respondents indicated that there are a good number of service providers for healthcare that included government, private and CSOs. The capacity of healthcare services provided by the health center/hospital depends on the physical infrastructure development and organisational capacity of the facility. Nonetheless most of the healthcare centers handled child immunisation. The survey revealed respondents proportions in relations to the types of healthcare facilities they received healthcare services most. Therefore a total of 256 out of the 282

Table 5. Multivariable logistic regression of rating CSO health care by the survey respondents.

\begin{tabular}{|c|c|c|c|}
\hline Variable & Variable level & OR [CI, 95\%] & P-value \\
\hline Gender female or male water & Female vs. male & $0.49[0.25 .7-0.98]$ & 0.0045 \\
\hline Education level of the respondents & Tertiary level vs. no any formal education & $0.72[0.57-0.89]$ & 0.0001 \\
\hline Household owning a Television & Yes vs. no & $2.4[1.38-4.19]$ & 0.002 \\
\hline Household owning a cell phone & Yes vs. no & $3.7[1.75-7.89]$ & 0.001 \\
\hline Household owning a bicycle & Yes vs. no & $2.19[1.27-3.75]$ & 0.005 \\
\hline Household having a separate animal house & Yes vs. no & $0.09[0.042-1.99]$ & 0.0001 \\
\hline Household having a functional food store (enguli) & Yes vs. no & $2.31[1.37-3.89]$ & 0.002 \\
\hline Distance to the health centre & $3 \mathrm{~km}$ or more vs. below $1 \mathrm{~km}$ & $4[2.99-5.67]$ & 0.0001 \\
\hline
\end{tabular}


respondents, i.e. 93\% of the respondents received health care services including child immunisation from governments, private and CSOs health centers. While on 18 out 282 respondents, i.e. $7 \%$ received healthcare services from government health facilities only. Observations have also complimented that child immunisation services it is both the government and Non-governmental organisation health centers that offer this service.

Results indicated that 273 out of 282 respondents i.e. $97 \%$ of the survey respondents' perceived that CSOs healthcare facilities are a pillar in health care service delivery in the district. Only 9 out of the 282 respondents i.e. $3 \%$ said that either they don't know what is all about CSO and healthcare is concerned or they had a negative attitude towards CSOs in healthcare service delivery.

\section{DISCUSSION}

The greater proportion of the respondents being females (78\%) is not surprising and therefore implies that more females participated in this survey and were studied than males. It also explains that the patriarchal nature of the African societies [19] where by practice women are prepared to care for the children and other domestic household chores including giving health care such as child immunisation. It could therefore be argued that there are gender concerns in terms of gender roles and health care delivery system. This could be a new forthcoming research concept. Multivariable logistic analysis indicated that females are 0.49 times less likely to rate the CSO in health care service delivery better compared to their male counterparts (since males are coded 1 and females coded 0 ). This also means that males rate CSO health care services better than females by $49 \%$. The confidence intervals show that there is a significant relationship. The reason for this is not clear however, it is envisaged that women attend for health services (general healthcare including children immunisation) more often than men, therefore have seen the challenges associated with health care services. For example encountering problems of long queues and delays at the hospital without services such drugs, and vaccines compared to their men. It is for the same reason that while at immunization centers, the majority were women, meaning men rarely do visits the health centers and get a chance to compare the health care at CSOs.

Earlier descriptive statistics results revealed that over $50 \%$ of the respondents had attained up to primary level. This is still low levels of formal education as evidenced by over $50 \%$ of the respondents have attained only up to primary school level of education despite the short distances travelled by the study communities to access primary school services. Therefore, it is important to understand that the education levels are likely to significant impact on the healthcare service delivery and influence the health seeking behavior (HSB) of the community. Education is likely to affect the capacity of the community to appreciate the value of healthcare access and acceptability from the various health service providers (government, NGOs, traditional healers etc.). Whereas according to a study done in Jamaica [20] showed that participants with less than secondary school education were more likely to be non-compliant to child immunization programs, this study indicated that there was a significant relationship between CSOs health care rating and level of education of the respondents. The educated community members are less likely to rate the CSO better than those that are not educated. The reason for this is not known however, education is tool for access knowledge and therefore make informed decisions. The educated respondents therefore have other options for healthcare besides CSO health care services. This therefore leaves the uneducated viewing the CSO health care as the best or better health care provider. It is important however, for a study to be done to compare CSOs and other health service providers such as government and traditional healthcare services etc and be able to relate the findings to different education levels. It is unfortunate this study could not extensively generate more information in this line of research.

We observed that there is a significant relationship between distance to health facility and rating of CSO. Individuals who travelled more than one $\mathrm{km}$ ( 2 above) are 0.41 times less likely to rate the services of CSO as better. Descriptive statistics further showed that more than 50\% of the study population travelled long distances over 2 kilometers in order to access the CSO health care services. This study has therefore revealed that CSOs geographical location constraints ultimately impacts on the distance travelled by the community members. Therefore, access to CSOs health care facilities is key important limiting factor indicated in this study. Thus, this calls for urgent need to address this hindrance of the community through nearby provision of more CSO health care or other health services to the community.

A statistically highly significant relationship has been observed from multivariable logistic regression analysis where those individuals (households) who have televisions and who watch at home are 2.4 times more likely to rate the activities of CSOs healthcare as good. The findings were with a p-value of 0.002 and 95\%CI of 1.38 4.19. The socioeconomic category with televisions (TVs) perhaps visit the centers for health services after they have watched health education programs offered by the CSO health facilities compared to those who don't have televisions access at all in their homesteads. The study indicate that functional Television (TV) were present in only 75 households (i.e. 27\%) and the rest of the respondents 
(207 out of the total 282 respondents ) i.e 73\% households did not own a television (TV). The study therefore brings out clearly that socio-economic status of the individuals greatly determines the level of access to CSO healthcare. These findings relate to the study done in Nigeria [21] that found most households owned functional radios, kerosene lamps. Bicycles and motorcycle cars and generators were least commonly owned assets. This study further indicates the high level of inequalities and the impact of that on healthcare delivery. From the study, we observe that few individuals own television, meaning that the majority do not access the information related to health that is relayed through this kind of media to community. It is therefore important to design programs after understanding the communication channels- media common to a wide range of people. However, this communication gap is addressed by using other forms of communication channels such as radio messages (since this study has found that every respondent owned a radio).

The study showed that seventy five percent of the respondents' i.e. 212 out of the 282 respondents (212/282) owned cellphones. Twenty five (25\%) percent did not own any cellphones. This finding is further consolidated by the fact that that those respondents who had cellphones with them are 3.7 times more likely to rate the activities of CSOs as better and have access to the CSO healthcare services compared to those who don't have cellphones. This result showed a statistically high significance with a p-value of 0.001 and $95 \%$ CI of $1.75-7.89$. This could be explained by the fact that the ability to communicate via mobile phone technology through calling or texting short messages among those individuals who have mobile phones. This therefore allows those individuals with cellphones to mobilize and organize themselves for healthcare programs including immunization days, family health days or other health services offered at the various healthcare facilities. However, this might have not been the case with the group without mobile hence they are likely to be left out and miss on some of the important health programs offered at the healthcare facilities. In turn this category will most likely rate the CSOs health services differently. This finding therefore reveals a new innovation of study where the role of mobile phone technology in health care delivery system could be a subject of interest for further research.

A statistical analysis showed a high significant relationship between households with food stores (eguli) and the study showed that those household are 2.3 times likely to rate the CSO health care facilities as better than those who do not have a food stores. This is also highly significant relationship with a p-Value of 0.002 and confidence interval at 95\%CI of 1.37 - 3.89. Physical structure assessments at the two selected Holy family Virika (HFV) hospital revealed that the CSO hospital also organizes health talks on before the immunization exercise at the center and also while on outreach visitation program in the various catchment areas of the hospital. Apart from child immunization, these health talks also cover a component of improved nutrition of the children. The mothers with children who have reached 6 months are advised and demonstrated to how to prepare nutritive foods (commonly called ekitobeero). The foods stored therefore not only helps to feeding the children but also can be very useful food for the adults too.

It is therefore probable that those community members who attended such health talks have benefited and have also opted to keep different forms of foods at households in the stores. Food stores not only play a key role of improved nutrition at household level but also helps in times of food scarcity (drought periods). According to the [22] health promotion is recognized as a very important strategy, in line with the principles of primary health care and reaching out to the under-served populations. Further, presents tools of health promotion that can be used to encourage community action for health, foster healthy lifestyles, and create conditions conducive to good health, even when resources are severely limited. Similarly, this calls for the corresponding need to intensify health promotion in the Kabarole district in particular and Uganda in general. However, this study descriptive analysis results showed that only $127 / 282$, i.e. $45 \%$ confirmed having functioning food stores (enguli) in their households. There is urgent need therefore to sensitize the community and enhance awareness campaigns on the role of food stores in ensuring food secure homesteads and improved nutrition for better health and sustainable livelihoods.

More than half of the respondents owned bicycles, i.e. 158of the 282 households interviewed, i.e. 56\% of the respondents as revealed from the descriptive statistical analysis. Contrary to the study done in Nigeria [21] where bicycles, and motorcycle cars and generators were least commonly owned assets, this study showed that at least more than half of the study population owned a bicycle as mode of transport to access healthcare services including immunization of children.

In addition, multivariable logistic analysis further revealed that households with bicycles as modes of transport to the health center are 2.2 times more likely to rate and value the role of CSOs health care services compared to those who did own a bicycle as means of transport commonly used to access health services. This relation is statistically significant with a p-value of 0.005 and $95 \%$ CI of 1.27 - 3.75. These findings therefore compliment on the findings from a case study done by [23] on intermediate means of transport (IMT) where the bicycle was found to be the most common IMT in SSA, and it is used to improve the efficiency of productive tasks, and to serve as a link between farms and villages, nearby road net- 
works, and market towns. The same case study further revealed that the use of bicycles in eastern Uganda where they are a means of generating income for rural traders and for urban poor who work as bicycle taxi-riders. Contrary to [23] from the gender perspective, bicycle riding by women is not a common practice in Kabarole district. More so, the nature of the terrain is not well suited for bicycle riding as there many hills and valleys unlike the eastern Uganda scenario. However, bicycles are the common modes of transport for the deep rural communities to access many rural towns or trading centers and main road networks. This also helps communities to easily access the health care services that are distant located.

There is growing body of research towards efforts to prevent shared diseases from humans to be transmitted to animals and vice varsa. This is referred to as one health approach. In this study, more than 100 out of the 282 respondents would access livestock extension services, In addition, statistical analysis showed a significant relationship with CSOs health care rating and the respondents staying in homes with separate animal houses. Having separate animal house (Kraal) for livestock is less likely to rate the CSO healthcare better than those without animal houses (kraals). This relation is statistically significant with a p-value of 0.0001 and $95 \% \mathrm{CI}$ of 0.042 - 1.99. This is could be explained by the fact that homes that do not separate animal are likely to visit the CSO health care services than those with animal houses. These prevent themselves not only from visiting the CSOs healthcare services but also prevent themselves from diseases transmissible from animals to humans and vise-varsa (Zoonoses), therefore this category rarely visits the CSOs compared to those who do not have animal houses separated from the main human shelter who perhaps visits the CSO health centers. This finding therefore concurs with [22] where health promotions strategies on primary health care and reaching out to the disadvantaged and underserved populations. Further [22] argues that there is need to give people a greater chance to take control over conditions affecting their health. These findings therefore indicate that with livestock extension services delivery and hospital outreach programs, the communities through having animals shelters separate, it means that people are able to prevent diseases which originate from animals hence applying the first principles of disease control of "prevention is better than cure" approach.

\section{CONCLUSION}

Community socioeconomic factors and the geographical location of the CSO health care strongly determine the operations and the roles of the CSO healthcare services including child immunization in Kabarole district, Uganda. This study demonstrates that socioeconomic status of communities determines the affordability of the commu- nity and accessibility to CSO healthcare centers. Therefore, further studies are needed to be done to assess the extent CSOs engaged in healthcare whether a blessing or a curse to healthcare delivery system in Uganda. In addition, studies focusing on other healthcare services provided by CSO healthcare delivery systems need to be studied.

\section{AUTHORS' CONTRIBUTIONS}

Clovice Kankya contributed to the design, data collection, drafting and writing of the manuscript. Annah Akandinda contributed to data collection, data analysis and drafting of the manuscript. Charles B. Rwabukwali contributed to conception, design, supervision and drafting of the manuscript. All authors have read and approved the final manuscript.

\section{ACKNOWLEDGEMENTS}

We would like to thank The Uganda National NGO forum for the financial support. Special thanks to Mr. Festus Kahigwa at Uganda National NGO Forum. Authors also thank: Joshua Mwesige and Ms Violet Nyakaisiki for the field research assistance. Special thanks go to the mothers who were immunising their children in KIDA and Holy Family Virika Hospitals at the time of research for their participation in this study.

\section{REFERENCES}

[1] Anheier, H.K. (2004) Civil society: Measurement, evaluation and policy. Earthscan, London.

[2] WHO (2002) WHO interaction with civil society and nongovernmental organizations. WHO, Geneva.

[3] Lamptey, P. and Piot, P. (1990) The handbook for AIDS prevention in Africa. Family Health International, Durham.

[4] Mckee, M. and Healy, J. (2000) The role of the hospital in a changing environment. Bulletin of the World Health Organization, 78, 803-810.

[5] Clayton, A., Oakley, P. and Taylor, J. (2000) Civil society organization and service provision civil society and social movement program. Paper No. 2 October, 2000, United Nations Research Institute for Social Development.

[6] WHO (2001) Strong alliances: The role of civil society organisation in health, civil society initiative. External relations and Governing bodies. Discussion Paper No. 1, World Health Organization, Geneva.

[7] Putnam, R. (1993) Making democracy work: Civic Traditions in modern Italy. University Press, Princeton.

[8] Gellner, E. (1994) Conditions of liberty: Civil society and its rivals. Penguin, Harmondsworth.

[9] Bermeo, N. and Nord, P. (2000) Civil society before democracy: Lessons from nineteenth-century Europe. Rowman \& Littlefield, Lanham.

[10] Steele, D.R. (2000) United Nations reform, civil and some- 
times uncivil society. Transnational Association, 52, 282290.

[11] The Asia Foundation (2008) Training needs assessment of civil society organisations in Vietnam: Organisational development and community mobilisation in the policy and law making process. TAF, Hanoi.

[12] Mkandawire, T. (1999). Social science and democracy: Debates in Africa. African Sociological Review, 3, 20-24. doi:10.4314/asr.v3i1.23154

[13] UNDP (2010) Beyond the midpoint: Achieving the millennium development goals. UNDP.

[14] Katusiimeh, M.W. (2006) Civil society organisations and democratic consolidation in Uganda. African Journal of International Affairs, 7, 99-116.

[15] Nanna, T., Makubuya A.N. and Nakirunda, M. (2002) A report of study on civil society in Uganda. Norad Study on Civil society in Uganda, Kampal.

[16] Kwesiga, B.J. and Ratter, J.A. (1993) Realizing the development potential of NGOs and community groups in Uganda. GoU/MoFEP.

[17] UBOS (2009) National service delivery survey report, 2008. UBOS, Kampala.
[18] Kish, L. (1965) Survey sampling. John Wiley and Sons, Inc., New York.

[19] Coetzee, D. (2001) South African education and ideology of patriarchy. South African Journal of Education, 21, 300304.

[20] Shuaib, F., Kimbrough, D., Roofe, M. and McGwin Jr., J.P. (2010) Factors associated with incomplete immunisation among residents of St. Mary parish, Jamaica. West Indian Medicine Journal, 59, 103-121.

[21] Onwujekwe, O., Hanson, K. and Uzochukwu, B. (2012) Examining inequalities in incidence of catastrophic health expenditures on different healthcare services and health facilities in Nigeria. PLOS One, 7, e40811.

[22] WHO (1994) Health promotion and community action for health in developing countries. World Health Organization, Geneva.

[23] Malmberg, C.C. (1994) Case study on intermediate means of transport (IMT) Bicycle and rural women in Uganda. The World Bank and Economic Commission for Africa SSATP Working Paper No. 12, Sub-Saharan Africa Transport Policy Programs (SSATP). 